\title{
ULTRAPASSANDO FRONTEIRAS: UM ESTUDO DAS INTER-RELAÇÕES CULTURAIS ENTRE ACEVEDO DÍAZ, EUCLIDES DA CUNHA E SEUS TRADUTORES - ALDYR GARCIA SCHLEE E BENJAMÍN DE GARAY
}

\author{
Mitizi de Miranda Gomes - UFRGS \\ Mitizi de Miranda Gomes é doutoranda em Literatura Comparada pela Universidade Federal do Rio Grande do Sul.
}

RESUMO: Pour ajouter une nouvelle nuance à la manière de comprendre les productions d'Eduardo Acevedo Díaz et d'Euclides da Cunha, on a cherché des études sur traduction qui se configurent comme une excellente contribution pour comprendre comment les traducteurs transfigurent l'oeuvre et créent un nouveau texte. Ainsi les traveaux de d'Aldyr Garcia Schlee et Benjamín de Garay sont d'extrême importance pour les études de Os Sertões et de l'oeuvre de l'auteur uruguayen.

PALAVRAS-CHAVE: Euclides da Cunha. Eduardo Acevedo Díaz. Teoria da Tradução.

\begin{abstract}
As obras literárias não estão fora das culturas, mas as coroam, e na medida em que essas culturas são invenções seculares e multidudinais, fazem do escritor um produtor que trabalha com as obras de inumeráveis homens. Um compilador, teria dito Roa Bastos. O genial tecelão, na vasta oficina histórica da sociedade americana.
\end{abstract}

Ángel Rama

Trabalhar as obras de Eduardo Acevedo Díaz e de Euclides da Cunha numa perspectiva comparatista necessita tomá-las como textos fundacionais ${ }^{\mathrm{ii}}$, considerando seus projetos de escrita de, a partir da história de seu país, refletir acerca de sua identidade. Contudo, as diferenças existentes entre elas adquirem dimensões fundamentais para o estudo, uma vez que o cunho literário da primeira está ligado também ao fato de que estão presentes nela uma gama de personagens fictícias, as quais se imbricam à história da República Oriental de forma simbiótica. Os Sertões, por sua vez, caracteriza-se como "um livro de forma científica e historiográfica", embora com pretensões literárias, conforme afirma Berthold Zilly ${ }^{\text {iii }}$. Agregado ao projeto de delimitação identitária, está a definição das diferentes culturas presentes em seus países, o que ajuda a entender a sua própria, pois como nos lembra Cornejo Polar, baseado nos estudos de Edward Said, "a configuração da imagem do outro é uma das estratégias mais comuns para definir a figuração de si mesmo"iv.

Ao analisar os textos Facundo e Os Sertões, Zilly comenta sobre o projeto historiográfico de ambos, destacando a necessidade de comporem um "retrato abrangente, cientificamente fundamentado, da natureza e da sociedade de uma região periférica e, a partir dela, de todo um país em formação". Para o crítico, "em ambos os casos esse remoto espaço rural e semi-selvagem estava ou parecia em descompasso com a missão civilizatória do país, rebelando-se contra ela"v, o que nos faz inferir, então, que os narradores heterodiegéticos em questão comportam-se como observadores capazes de detectar os problemas e dar a eles possíveis respostas.

Paco Espínola, ao escrever sobre a obra de Acevedo Díaz, mostra suas diretrizes e as corrobora, pois acredita, assim como seu mestre, que através da literatura devemos "salvar la mayor extensión posible del pasado para que siga actuante en el presente a fin de ir «formando» la nación. Porque todavía no somos del todo una nación"vi , o que Pablo Rocca complementa, dizendo que Espínola "apela, entonces, al estímulo de la memoria oral, para que se trasmita de generación en generación los caracteres colectivos a través de las historias de la nación"vii. Entretanto, percebemos que Espínola reconhece na obra de Acevedo o destaque dado ao individual, embora almejando uma construção do ideário nacionalista.

Más que nunca precisamos hoy elementos aglutinantes, factores que consigna por sobre las diferencias individuales, enérgicos nexos colectivos. Difundir y explicar la obra de Acevedo Díaz tiene ese valor. Y en el más alto grado. Porque muy pocos de los nacidos en este suelo presentan tantos elementos y con tanta grandeza ${ }^{\text {viii }}$.

Evidentemente devemos destacar que tanto no texto de Euclides quanto no de Acevedo existe a fronteira entre o eu e o outro; fronteira esta que permite analisar o outro como alguém diferente do eu. Tais fronteiras nem sempre são transpostas, comportando-se, muitas vezes, como limites. É o caso do conto Cueva del tigre ${ }^{\mathrm{ix}}$, de Acevedo Díaz, que retrata o episódio da limpeza étnica feita no Uruguai, por ordem do presidente Fructuoso Rivera. Neste conto, além de constatar que o efeito estético se sobrepõe à retratação da realidade (pois ao publicar tal conto o autor recebe uma carta de Modesto Polanco ${ }^{\mathrm{x}}$ contestando algumas caracterizações, entretanto não realiza modificações no texto, mantendo a construção poética em detrimento dos fatos ${ }^{\mathrm{xi}}$ ), e considerando a ideologia de Acevedo de buscar uma uniformização identitária e nacional, vemos que não reconhece a si mesmo no povo indígena - este é o outro que não deve se confundir com os cidadãos uruguaios. 
Embora tenhamos vários textos que tentem firmar um conceito de nação, no caso do Brasil, da Argentina e do Uruguai, sabemos que, até hoje, a América Latina está por formar-se. Se antes tínhamos a problemática étnica, como vemos no texto de Sarmiento, por exemplo, em que a diversidade de um país atrapalha a construção de sua própria identidade, hoje essa questão se mantém, pois são justamente as diferenças culturais de um povo que não permitem pensar em uma homogeneidade. Por isso, pensar hoje em definir a nação é esquecer que a unificação de qualquer pensamento pode acabar com a relação dialética entre as culturas e construir um resultado pasteurizado. É o que nos lembra Schlee, em seu texto chamado "Integração cultural regional", ao dizer que os estudos de diferentes áreas do conhecimento remete-nos "à questão das identidades regionais e nacionais e [abre] espaço para a conceituação de identidades plurais e para a abertura de um diálogo cultural que ajude a impulsionar o que poderia chamar de globalização por baixo"xii.

Schlee fala, ainda, da existência de vários brasis, que desafia a questão da integração nacional, o que é corroborado pelas afirmações de Lígia Chiappini, quando diz que "não há como negar que, cada vez mais, as identidade são plurais e as nações sempre se compuseram na diferença, mais ou menos escamoteada por uma homogeneização forçada, em grande parte artificial"xiii. Vale salientar também o que nos afirma Homi Bhabha acerca da concepção de culturas homogêneas.

Os próprios conceitos de culturas nacionais homogêneas, a transmissão consensual ou contígua de tradições históricas, ou comunidades étnicas "orgânicas" - enquanto base do comparativismo cultural -, estão em profundo processo de redefinição. $\mathrm{O}$ extremismo odioso do nacionalismo sérvio prova que a própria idéia de identidade nacional pura, "etnicamente purificada", só pode ser atingida por meio da morte, literal e figurativa, dos complexos entrelaçamentos da história e por meio de fronteiras culturalmente contingentes da nacionalidade [nationhood] moderna.xiv

A partir disso, concluímos que é mais fácil pensar em homogeneização cultural no século XIX, seja nos auspícios do Romantismo, seja no cientificismo emergente do fim de século, pois, agora, cada vez mais nos distanciamos deste ideário, pois falamos de multiculturalismo dentro de um mesmo espaço político e geográfico, ou de regiões culturais em diferentes espaços geográficos, dados os traços comuns existentes entre grupos de diferentes países, que é o caso da identificação da cultura gauchesca do Rio Grande do Sul com as culturas do Uruguai e da Argentina.

Refletir acerca da proximidade cultural entre o Rio Grande do Sul, o Uruguai e a Argentina traz sempre à tona discussões sobre fronteiras e limites. Entretanto, expandir este espaço do Rio Grande do Sul para o resto do Brasil foge ao que chamaríamos de região com práticas culturais semelhantes, ou seja, subverte a comarca. Com sua dimensão quase continental, o Brasil caracteriza-se por possuir regiões culturais dentro de si, o que já foi discutido por Ángel Rama, quando afirma que tais regiões são "extensas e nitidamente delineadas, [...] fazendo com que o mapa regional brasileiro seja equivalente ao mosaico de países independentes do hemisfério hispanoamericano" "xv . O crítico destaca, também, a existência de regiões culturais que subvertem o limite oficial, que é o caso do "estado do Rio Grande do Sul, brasileiro, [que] mostra vínculos maiores com o Uruguai, ou a região argentina dos pampas, do que com o Mato Grosso ou o Nordeste de seu próprio país" "xvi.

Tania Franco Carvalhal, em Fronteiras da crítica e crítica de fronteiras, salienta a necessidade de se definir o termo fronteira e o compreende "como uma espécie de 'convenção estruturante', um espaço de divisa e de delimitação que demarca diferenças, afirma identidades e origina necessidades de representação" "xvii. Dessa forma, ao pensarmos na fronteira do pampa, vemos que esta serve tanto para mostrar que os países possuem peculiaridade, e por isso necessitam afirmar suas próprias representações, quanto para esclarecer que, ao serem ultrapassadas, denotam as semelhanças entre eles. Sem perder de vista a própria identidade, os países em questão, no que tange a estudos da representação do gaúcho do pampa, alertam sempre para o fato de que tal ícone ultrapassa fronteiras políticas, porque, antes de tudo, sabemos que se move em um ambiente comum aos três países, mantendo suas características, independente dos limites nacionais. Estudar a figura do gaúcho é, pois, ir além das fronteiras; é falar de si, mas também daquele que tem a mesma realidade cultural, embora em outro espaço político.

Ainda para Carvalhal, é preciso vislumbrar esses conjuntos culturais para realizar um "estudo dessas literaturas de zonas de contato ou zonas fronteiriças, pois elas emergem de espaços sociais onde as culturas se encontram"xviii. A partir disso, Tania Cavalhal salienta a importância das traduções dessas literaturas de fronteiras, supondo, ainda, que algumas traduções do espanhol possam integrar a literatura brasileira, como o caso do trabalho tradutório de Schlee, ou, como o espanhol interfere nas obras de autores gaúchos.

Quanto às questões tradutórias, vale lembrar duas traduções feitas por Schlee: uma da obra Facundo, de Sarmiento, outra de textos variados, de Acevedo Díaz, intitulada Pátria Uruguaia. Na primeira, Schlee realiza um trabalho de pesquisa minucioso, em que busca as diferentes publicações do mesmo texto, fazendo, então, um trabalho de crítica genética, e utiliza-as em sua tradução, mantendo elementos que são pertinentes ao que o autortradutor se propõe. O tradutor comenta que foi preciso domar Facundo, pois, em seu trabalho, "rememora-se o regional, retoma-se o arcaico e se tenta reavivar criativamente, em 1996, os matizes de uma linguagem perdida entre o neoclássico e o romântico, mas viva ainda na sua espontânea oralidade do discurso doutrinário de $1845^{\text {"xix }}$. Agregado a isso está o fato de que em seus critérios básicos destaca a necessidade de "se preservar os regionalismos, modismos e arcaísmos, traduzindo-os quando dicionarizados, ou explicando-os em notas de 
rodapé”; destaca-se, ainda, a explicação de que irá reproduzir algumas expressões conforme o regional, como "os estrangeirismos (traduzidos em notas de rodapé, se necessário), [...] as palavras intraduzíveis por qualquer

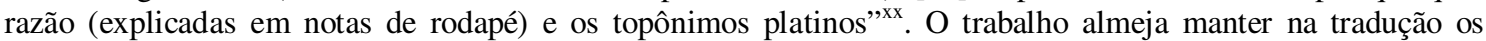
traços do texto original.

Quanto ao segundo trabalho tradutório de Schlee, de textos do autor uruguaio Eduardo Acevedo Díaz, vemos o quanto o autor-tradutor reconfigura-os. Schlee dá aos brasileiros uma outra obra que foi escrita por ele, qual seja, Pátria Uruguaia. Aqui, cabe destacar que, tal como nos lembra Carvalhal, temos a interferência do tradutor, que realiza uma releitura dos textos de Acevedo Díaz ${ }^{x x i}$. Schlee escreve uma obra coesa com fragmentos de romances e com contos do autor uruguaio, para provar a tese de que "o verdadeiro protagonista de suas obras épicas é a nacionalidade uruguaia",xxii

Ainda no âmbito da tradução, é importante destacar o trabalho feito por Benjamín de Garay, que traduziu para o espanhol em 1938 a obra Os Sertões. Na tradução citada, percebe-se uma preocupação em explicar em seu vocabulário inicial as palavras específicas da região nordeste do Brasil, como caatinga, chique-chique, jagunço, rapadura, entre outras, sem destacar, porém, aquelas palavras comuns à cultura do pampa, mas não tão comuns a Euclides da Cunha. As palavras gaúcho, bombachas, baguais, guaiaca, pingo, peleador, entreveros, movimentam-se naturalmente em seu texto, o que deixa claro que seus leitores não terão problemas ao ler, porque lhes são familiares. O trabalho de Garay foi publicado por diferentes editoras, recentemente, em 2003, Los Sertones ${ }^{\text {xiii }}$ foi reeditado com a mesma tradução feita em 1938, que é considerada a melhor feita para a língua espanhola. O exemplo dado corrobora a idéia de que a identidade cultural ultrapassa fronteiras políticas e mostra também a complexidade das relações entre as diferentes culturas envolvidas. Se, por um lado, Garay não necessitava traduzir os termos comuns à língua espanhola, por outro, necessitou compilar uma lista um tanto extensa de expressões referentes a outra região do Brasil, a nordeste. Também esse duplo movimento acontece na obra de Euclides; entretanto, não monta um glossário, mas, na edição estudada, as palavras do vocabulário rio-grandense estão grifadas. É importante salientar que há uma nota da editora dizendo que não houve intervenção nos textos originais ${ }^{\text {xxiv }}$.

Ainda no âmbito da tradução de Os Sertões, destaco um trabalho curioso feito por Enrique Pérez Mariluz, em Buenos Aires, 1941. Tal tradução possui 172 páginas, e é desnecessário alertar que se trata de uma edição compendiada, que exclui muitos trechos de seu texto. Entretanto, além de o tradutor possuir a mesma preocupação de Garay, de montar um glossário das palavras alheias a sua cultura, suprime a parte do texto em que há a descrição do gaúcho, a qual serve para se contrapor ao sertanejo, para enfim, destacar as características positivas deste, comparativamente àquele.

Diante dessas considerações vemos o quanto é importante o estudo das traduções com o fim de colaborar para as investigações acerca da problemática da fronteira. Também vale ressaltar que as questões identitárias dos estudos acerca da cultura estão ligados ao lugar em que o escritor (ou pesquisador) se encontra, ou seja, nos casos de Euclides e Acevedo, também nos de Schlee e de Garay, qual o locus de enunciação e como se definem diante dos demais, dos diferentes. Para o tradutor, importa perceber as diversidades culturais, para que consiga traduzir para sua cultura essa diferença. Assim, percebe-se que são as inter-relações entre as culturas que compõem o todo, e é a percepção dessa coexistência cultural que facilitará ao estudioso identificar "o 'específico', aquilo que caracteriza as 'tensões' nesse processo" ${ }^{\text {xxv }}$. Ainda para Carvalhal, estudar essa literatura de zonas de fronteiras é

Observar como elas se afirmam e identificam um processo de diferenciação, ao exprimir contextos divergentes. A aparente unidade que as recobre oculta a diversidade que caracteriza o conjunto e lhe dá sentido. Cabe perguntar: Que categorias as articulam? Como representam a alteridade? Como se manifestam as identidades na diferença? xxvi

Assim, buscar definir o $e u$ através destes estudos é, primeiramente, como nos lembra Mário J. Valdés na introdução feita à edição brasileira de $O$ Condor voa, de Antonio Cornejo Polar, não esquecer que

a literatura latino-americana está formada por vários sistemas literários que são parte da heterogeneidade étnico-social da América Latina, mas estes sistemas não são independentes: produzidos dentro de um processo histórico comum, relacionam-se entre si mediante vínculos de contradição que essa mesma história explica, e constituem, como conjunto, uma totalidade igualmente contraditória.xxvii

Euclides estudou no sertão uma zona cultural muito diversa da sua, e traduziu, de certa forma, essa "heterogeneidade étnico-social" do Brasil, diferenciando os tipos habitantes do país, de acordo com a região, e delimitando as fronteiras culturais. Trabalho semelhante fez Acevedo, pois também traduziu "as histórias" de seu país, mostrando que a identidade uruguaia nasceu da delimitação do território e da luta para mantê-lo. Como afirma Pablo Rocca, acerca do projeto da tetralogia do autor uruguaio,

El pasado se justifica en su misma heroicidad, en el embrión nacional que es la guerra popular por la independencia (Ismael) o el rechazo al poder del ocupante extranjero (Nativa, Grito de Gloria) o el enfrentamiento entre hermanos para hacer una nación nueva, pero aún tambaleante (Lanza y sable).xxviii

No âmbito da tradução propriamente dita, Schlee, ao traduzir as obras de Sarmiento e Acevedo, mesclou culturas. No caso do primeiro, fez o possível para aproximar o texto de Sarmiento ao leitor brasileiro, sem restringi-lo à zona de identificação cultural, recheando seu trabalho de notas de rodapé e explicações de todos os 
tipos. Já ao traduzir Acevedo, Schlee constrói um novo texto, este sim, mais restrito à região cultural, dando-lhe até um título próprio. Neste caso, Schlee traduz uma realidade.

Garay aproximou culturas com suas traduções, pois deu aos países de língua espanhola uma obra que mostra as diversidades culturais do Brasil, indo, tal como Schlee em Facundo, além da tradução lingüística. $\mathrm{O}$ valor desses trabalhos tradutórios reside no fato de que

Cada texto es único y, simultáneamente, es la traducción de otro texto. Ningún texto es enteramente original porque el lenguaje mismo, en su esencia, es ya una traducción: primero, del mundo no-verbal y, después, porque cada signo y cada frase es la traducción de otro signo y de otra frase. Pero ese razonamiento puede invertirse sin perder validez: todos los textos son originales porque cada traducción es distinta. Cada traducción es, hasta cierto punto, una invención y así constituye un texto único. xxix

A importância do estudo das traduções destes textos, então, reside no fato de que todos foram reconfigurados a partir da identidade cultural de cada tradutor. Cabe analisar de que forma essa realidade está expressa na linguagem, no novo texto feito em outra língua; ou ainda, de que forma o tradutor recebe essa realidade, mostrando quais as necessidades que os possíveis leitores terão e como foram sanadas. É o que nos lembra Carbonell i Cortés, ao definir o conceito de tradução cultural e de explicar que a teoria cultural contemporânea "trata de la relación entre las condiciones de producción de conocimiento en una cultura dada y cómo un saber procedente de un contexto cultural diferente se relocaliza y se reinterpreta según las condiciones en las que tiene lugar todo conocimiento" $\mathrm{xxx}$.

\section{REFERÊNCIAS BIBLIOGRÁFICAS}

ACEVEDO DÍAZ, Eduardo. Cuentos completos: edición crítica, prólogo, bibliografías y notas: Pablo Rocca. Montevideo: Banda Oriental, 1999.

BHABHA, Homi. O local da cultura. Belo Horizonte: Ed. UFMG, 2003.

CARBONELL I CORTÉS, Ovidi. Traducir al otro: traducción, exotismo, poscolonialismo. Cuenca: Ediciones de la Universidad de Castilla-La Mancha, 1997.

CARVALHAL, Tania Franco. O próprio e o alheio: ensaios de literatura comparada. São Leopoldo/RS: Ed. Unisinos, 2003.

CHIAPPINI, Lígia. "Multiculturalismo e identidade nacional”. In: MARTINS, Maria Helena (org.). Fronteiras culturais - Brasil, Uruguai, Argentina. Cotia/SP: Ateliê Editorial, 2002.

CUNHA, Euclides da. Los Sertones. Buenos Aires: Fondo de Cultura Económica, 2003. (Prólogo de Florencia Garramuño, tradução de Benjamín de Garay)

CUNHA, Euclides da. Os Sertões. 4ª edição. Rio de Janeiro: Record, 2001.

MARTINEZ BARBOSA, Rodolfo (notas). La carta de Modesto Polanco a Eduardo Acevedo Díaz. $<$ http://planeta.eltimon.com/india/ceci/ceci_e3.htm> Acessado em: 24/05/2004.

PAZ, Octavio. Sobre la traducción. Disponível em: <http://www.fortunecity.com/?sid=fcfootergif > Acessado em: $17 / 11 / 2004$.

POLAR, Antonio Cornejo. O condor voa: literatura e cultura latino-americanas. Belo Horizonte: UFMG, 2000.

RAMA, Ángel. "Literatura e cultura". In: AGUIAR, Flávio, VASCONCELOS, Sandra G.T. (orgs.). Ángel Rama: literatura e cultura na América Latina. São Paulo: EDUSP, 2001, p. 239-280.

RAMA, Ángel. "Regiões, culturas e literaturas". In: AGUIAR, Flávio, VASCONCELOS, Sandra G.T. (orgs.). Ángel Rama: literatura e cultura na América Latina. São Paulo: EDUSP, 2001, p. 281-336.

ROCCA, Pablo. "Historia, relato, nación: el 'diálogo' Acevedo Díaz - Espínola”. Publicado em: Narrativa rural en la región entre los años veinte y cincuenta. Actas de las Jornadas. Montevideo, Universidad de la República, 2002, p. 17-24.

SCHLEE, Aldyr Garcia. "Domar Facundo". In: SARMIENTO, Domingo Faustino. Facundo: civilização e barbárie no pampa argentino. Porto Alegre: Ed. UFRGS/EDPUCRS, 1996, p. 7-27.

SCHLEE, Aldyr Garcia. "Integração cultural regional". In: MARTINS, Maria Helena (org.). Fronteiras culturais - Brasil, Uruguai, Argentina. Cotia/SP: Ateliê Editorial, 2002.

SCHLEE, Aldyr Garcia. "Uma antologia: Eduardo Acevedo Díaz aos pedaços, mas de corpo inteiro". In: ACEVEDO DÍAZ, Eduardo. Pátria Uruguaia. Porto Alegre: IEL, 1997, p. 9-13.

VALDÉS, Mário J.. "Conversação com Cornejo Polar sobre a história da literatura latino-americana". In: POLAR, Antonio Cornejo. O condor voa: literatura e cultura latino-americanas. Belo Horizonte: UFMG, 2000.

ZILLY, Berthold. A barbárie: antítese ou elemento da civilização? Do Facundo de Sarmiento a Os Sertões de Euclides da Cunha. Disponível em: <http://www.artnet.com.br/gramsci/arquiv157.htm> Acessado em: 03/07/2004. (Originalmente publicado em De sertões, desertos e espaços incivilizados. Rio de Janeiro: Faperj/Ed. Mauad, 2001)

Notas: 
i RAMA, Ángel. "Literatura e cultura". In: AGUIAR, Flávio, VASCONCELOS, Sandra G.T. (orgs.). Ángel Rama: literatura e cultura na América Latina. São Paulo: EDUSP, 2001, p. 247.

${ }^{\text {ii }}$ Considerando a definição de Berthold Zilly. Ver: ZILLY, Berthold. A barbárie: antítese ou elemento da civilização? Do Facundo de Sarmiento a Os Sertões de Euclides da Cunha. Disponível em: <http://www.artnet.com.br/gramsci/arquiv157.htm> Acessado em: 03/07/2004. (Originalmente publicado em De sertões, desertos e espaços incivilizados. Rio de Janeiro: Faperj/Ed. Mauad, 2001)

iii ZILLY, Berthold. Idem.

iv POLAR, Antonio Cornejo. O condor voa: literatura e cultura latino-americanas. Belo Horizonte: UFMG, 2000, p. 56.

${ }^{\mathrm{V}}$ ZILLY, Berthold. Idem.

${ }^{\text {vi }}$ ESPÍNOLA, Paco (artigos de El Pais, 1951). Apud: ROCCA, Pablo. "Historia, relato, nación: el 'diálogo' Acevedo Díaz - Espínola". Publicado em: Narrativa rural en la región entre los años veinte y cincuenta. Actas de las Jornadas. Montevideo, Universidad de la República, 2002, p. 17-24.

vii ROCCA, Pablo. Idem.

viii ESPÍNOLA, Paco. Op. Cit.

${ }^{\text {ix }}$ ACEVEDO DÍAZ, Eduardo. Cuentos completos: edición crítica, prólogo, bibliografías y notas: Pablo Rocca. Montevideo: Banda Oriental, 1999, p.50-60.

× MARTINEZ BARBOSA, Rodolfo (notas). La carta de Modesto Polanco a Eduardo Acevedo Díaz. <http://planeta.eltimon.com/india/ceci/ceci_e3.htm> Acessado em: 24/05/2004.

${ }^{x i}$ Este estudo acerca do conto Cueva del tigre foi apresentado no IX Congresso ABRALIC 2004 (de 18 a 21/07/2004 - Porto Alegre/RS), por Mitizi Gomes, intitulado Fato e ficção: a literatura conta a história e auxilia na construção identitária - Eduardo Acevedo Díaz e a ficção uruguaia.

xii SCHLEE, Aldyr Garcia. "Integração cultural regional". In: MARTINS, Maria Helena (org.). Fronteiras culturais - Brasil, Uruguai, Argentina. Cotia/SP: Ateliê Editorial, 2002, p. 61.

xiii CHIAPPINI, Lígia. "Multiculturalismo e identidade nacional". In: MARTINS, Maria Helena (org.). Idem, p. 44.

xiv BHABHA, Homi. O local da cultura. Belo Horizonte: Ed. UFMG, 2003, p. 24.

${ }^{x v}$ RAMA, Ángel. "Regiões, culturas e literaturas". In: AGUIAR, Flávio, VASCONCELOS, Sandra G.T. (orgs.). Ángel Rama: literatura e cultura na América Latina. São Paulo: EDUSP, 2001, p. 282.

xvi RAMA, Ángel. Idem, ibidem.

xvii CARVALHAL, Tania Franco. "Fronteiras da crítica e crítica de fronteiras". In: O próprio e o alheio: ensaios de literatura comparada. São Leopoldo/RS: Ed. Unisinos, 2003, p. 154.

xviii Idem, p.157.

xix SCHLEE, Aldyr Garcia. "Domar Facundo". In: SARMIENTO, Domingo Faustino. Facundo: civilização e barbárie no pampa argentino. Porto Alegre: Ed. UFRGS/EDPUCRS, 1996, p. XXV.

${ }^{x x}$ Idem, p. XXVI.

${ }^{x x i}$ Esse estudo foi desenvolvido no texto de Mitizi Gomes, intitulado Aldyr Garcia Schlee e a tradução mosaico-estilhaçada de Acevedo Díaz em Pátria Uruguaia, apresentado no III FILE - Fórum Internacional de Língua Estrangeira (de 22 a 24/09/2004 - Pelotas/RS).

xxii SCHLEE, Aldyr Garcia. "Uma antologia: Eduardo Acevedo Díaz aos pedaços, mas de corpo inteiro". In: ACEVEDO DíAZ, Eduardo. Pátria Uruguaia. Porto Alegre: IEL, 1997, p. 10.

xxiii CUNHA, Euclides da. Los Sertones. Buenos Aires: Fondo de Cultura Económica, 2003. (Prólogo de Florencia Garramuño, tradução de Benjamín de Garay)

${ }^{\text {xxiv }}$ CUNHA, Euclides da. Os Sertões. $4^{\text {a }}$ edição. Rio de Janeiro: Record, 2001.

${ }^{x x v}$ CARVALHAL, Tania Franco. Op. Cit., p. 164.

xxvi Idem, p. 164-5.

xxvii VALDÉS, Mário J.. "Conversação com Cornejo Polar sobre a história da literatura latino-americana". In: POLAR, Antonio Cornejo. Op. Cit., p. 11.

xxviii ROCCA, Pablo. Op. Cit.

${ }^{x x i x}$ PAZ, Octavio. Sobre la traducción. Disponível em: <http://www.fortunecity.com/?sid=fcfootergif> Acessado em: 17/11/2004.

${ }^{x x x}$ CARBONELL I CORTÉS, Ovidi. Traducir al otro: traducción, exotismo, poscolonialismo. Cuenca: Ediciones de la Universidad de Castilla-La Mancha, 1997, p. 48. 